\title{
La ética de la representación en el documental
}

\author{
Pablo Lanza* \\ UBA-CONICET
}

Recibido: 12 de octubre 2015; aceptado: 14 de noviembre 2015

\section{Resumen}

A diferencia del cine de ficción, el documental se refiere a la realidad con intención de "veracidad expresa", razón por la cual los realizadores asumen un pacto tanto con los espectadores (a los que se asegura que los hechos representados son verídicos) como con los sujetos/personajes. Sin embargo, estas obligaciones no se encuentran delineadas de forma explícita, ya que el documental trabaja sobre la realidad de una forma creativa, motivo que no obliga a hablar de ética, entendida como códigos de comportamiento humanos. Estos códigos no son inalterables, sino que varían de sociedad en sociedad y de época en época, pero una de las constantes es la desigualdad de poder entre los sujetos retratados y los realizadores. Este artículo se propone indagar sobre una serie de ejes específicos como las condiciones necesarias para considerar al consentimiento otorgado como válido, las estrategias adoptadas para la realización de entrevistas y la representación de la muerte a partir del análisis de tres documentales argentinos recientes: Yo no sé qué me han hecho tus ojos(2003, Sergio Wolf y Lorena Muñoz), Yo presidente (2006, Gastón Duprat y Mariano Cohn) y Bye bye life (2008, Enrique Piñeyro).

Palabras clave: Cine documental | Personajes | Ética

\section{Resumen}

A diferencia del cine de ficción, el documental se refiere a la realidad con intención de "veracidad expresa", razón por la cual los realizadores asumen un pacto tanto con los espectadores (a los que se asegura que los hechos representados son verídicos) como con los sujetos/personajes. Sin embargo, estas obligaciones no se encuentran delineadas de forma explícita, ya que el documental trabaja sobre la realidad de una forma creativa, motivo que no obliga a hablar de ética, entendida como códigos de comportamiento humanos. Estos códigos no son inalterables, sino que varían de sociedad en sociedad y de época en época, pero una de las constantes es la desigualdad de poder entre los sujetos retratados y los realizadores. Este artículo se propone indagar sobre una serie de ejes específicos como las condiciones necesarias para considerar al consentimiento otorgado como válido, las estrategias adoptadas para la realización de entrevistas y la representación de la muerte a partir del análisis de tres documentales argentinos recientes: Yo no sé qué me han hecho tus ojos(2003, Sergio Wolf y Lorena Muñoz), Yo presidente (2006, Gastón Duprat y Mariano Cohn) y Bye bye life (2008, Enrique Piñeyro).

Palabras clave: Cine documental | Personajes | Ética

The ethics of representation in documentary film

\begin{abstract}
Unlike fiction films, documentary refers to reality with the intention of "expressing truth", which is why filmmakers have an obligation to both viewers (that represented facts are true) and to the subjects / characters. However, these obligations are not explicitly outlined, as the documentary treats reality in a creative way, which forces us to talk about ethics, understood as codesof human behavior. These codes are not unchangeable, but vary from society to society and from age to age, but a constant is the inequality of power between the subjects and the filmmakers. This article proposes to investigate a number of specific axes such as the necessary conditions to consider a given consent as valid, the strategies adopted to conducting interviews and the representation of death from the analysis of three recent Argentine documentary: Yo no sé qué me han hecho tus ojos (2003, Sergio Wolf \& Lorena Muñoz), Yo presidente (2006, Gastón Duprat \& Mariano Cohn) and Bye bye life (2008, Enrique Piñeyro).
\end{abstract}

Keywords: Documentary film | Characters | Ethics

\section{Introducción}

La diferencia más importante entre el cine de ficción y el documental no radica en una serie de procedimientos propios a cada discurso, sino en la relación que establecen con el mundo (profílmico) y los dilemas éticos y morales que tal vínculo supone. A pesar de que las implicancias éticas de los documentalistas son más mediatas que las del creador de ficción, no por eso su delimitación ha resultado sencilla. La ausencia de reglas escritas por

* pablohernanlanza@hotmail.com 
parte de la comunidad documental obliga a hablar de ética, de códigos de conducta humana. Recuperando a Carlos Mendoza, podríamos definir a la ética como una "teoría que explica el comportamiento moral del hombre en sociedad, y no es universal ni aplica a todo tiempo, sino que responde a las virtudes morales consagradas por sociedades determinadas" (2008, p. 56). La observación más importante que se desprende de dicha definición es el carácter temporal de los marcos de conducta que se puedan delimitar.

El abordaje a dicha temática en los estudios sobre el cine documental se ha focalizado sobre dos perspectivas: los deberes del realizador hacia el espectador y hacia el sujeto representado (Aufderheide et al., 2009; Nichols, 2007). La obligación del realizador hacia el espectador radicaría en garantizar que aquello que se representa realmente ocurrió, que los hechos se condicen con la realidad y que, por ende, no se lo está engañando. Para Bill Nichols el deber del realizador radica en ganarse la confianza del espectador en busca de una verdad superior (en Crowder-Taraborrelli, 2012); en primera instancia este punto no parecería ser demasiado complicado, pero la verdad resulta ser un tanto más compleja. Si tenemos en cuenta la famosa primera definición de John Grierson, "el tratamiento creativo de la realidad", podemos concluir que no se trata de la mera representación de la realidad, sino que incluye algo más, un aporte extra que lo situaría en un lugar especial, según Brian Winston, entre el arte y el periodismo, y por lo tanto complica la posibilidad de delimitar una serie de reglas de conducta. Según el teórico, "el documental no es ficción, pero tampoco es exactamente periodismo (...) A pesar que su anclaje en la 'realidad' requiere que se comporte éticamente, su deseo paralelo de que se le permita ser 'creativo' permite un grado de 'amoralidad' artística" (2005, p. 181). Al establecer su diferenciación con el periodismo, Winston argumenta que el documentalista suele establecer un compromiso con los personajes de la película, mientras que el fin del periodista es exponer cierto saber a su público. No obstante, resulta necesario señalar que en última medida tampoco se resume a que el periodismo cuenta con una ética específica, sino que la misma coincide con las obligaciones de cualquier ciudadano en una determinada sociedad (Pena de Oliveira, 2009). ${ }^{1}$ Uno de los ejemplos más renombrados sobre este desfasaje es el debate que surgió tras el estreno de Roger y yo (Roger and Me, 1989), en el que Michael Moore alteró la cronología de ciertos hechos para darle una mayor unidad dramática, sin hacer aclaraciones sobre la licencia tomada. ${ }^{2}$ Esta observación fue de hecho marcada por un periodista, y si aceptamos que "en un documental histórico, el orden de los eventos del mundo proyectado debe corresponder al orden cronológico de los eventos verdaderos" (Plantinga, 1997, p.120), es factible considerar a dicha licencia como un engaño.

A lo largo de los distintos períodos de la historia del documental los deberes del documentalista han variado, debido a que la aproximación hacia su referente ha ido mutando. Fernão Pessoa Ramos (2008), apoyándose en gran medida en las modalidades del documental de Nichols (1997), propone cuatro sistemas de valores éticos: educativo, imparcial, interactivo/ reflexivo, y modesto. La ética educativa concierne al documental clásico (o expositivo), y en ella el valor más importante es la divulgación de un saber que influya en el proceso formativo de un ciudadano. Fundado por el Estado, el estilo de la "ética educativa" se caracteriza por una fuerte presencia de la voz over, ausencia de entrevistas, filmación en locaciones y la utilización de personas comunes como actores. La escala de valores en este conjunto se encuentra en el propio contenido de los intereses que vehicula, sin considerar la posición del sujeto que enuncia. La ética de la imparcialidad se ajusta a la modalidad observacional y se caracteriza por la intención de captar la realidad sin interferencias y la crítica al sujeto enunciador del documental clásico. El objetivo en ella es ofrecer al espectador una ventana al mundo y otorgarle libertad para que pueda sacar sus conclusiones. La ética interactiva supone una crítica de conjunto a la imparcialidad, abogando por la admisión de su intervención en el mundo y revelando su construcción al espectador. Este conjunto de valores incluye a los documentales que demuestran indeterminación y explicitan tanto su intervención como sus herramientas de enunciación, favoreciendo la reflexión. Por último, la ética modestase refiere al documental que "habla, antes que nada, de sí mismo, para después, eventualmente, arriesgarse a vuelos más altos, en los cuales enuncia su condición en el mundo" (2008, p. 39). Dicha ética se condice, según el autor, con el sujeto posmoderno, y tiene su principal exponente en el documental en primera persona (modalidad performativa).

Esta suerte de periodización puede ser sometida a un conjunto de críticas, entre ellas las mismas que se han señalado en el modelo de Nichols, ${ }^{3}$ pero a grandes rasgos demuestra que la serie de consideraciones éticas en el documental se han ido transformando de la mano de sus cambios estéticos, por lo que no puede abordarse 
con el mismo criterio a cualquier documental. Su delineado permite contextualizar los principios que guiaron muchas decisiones que fueron sometidas a escrutinio a lo largo de la historia del cine documental: las denuncias de los peligros a los que Flaherty sometió a sus protagonistas en escenas como la pesca en Man of Aran o la caza de la morsa con armas primitivas y la construcción de un iglú partido al medio de mayor tamaño para poder ubicar a la cámara en Nanook of the North, ${ }^{4}$ las batallas reconstruidas en los documentales de propaganda durante la Segunda Guerra Mundial, ${ }^{5}$ y las alteraciones cronológicas del ya mencionado Roger y yo.

En cuanto al segundo eje, el compromiso ético con los sujetos retratados, la situación es aún más compleja. Los personajes no son una representación transparente de las personas, sino que constituyen "actores sociales" (Nichols, 1997) o "caracterizaciones" (Plantinga, 2007), debido las operaciones de simplificación que los documentales realizan. Mientras una persona posee cualidades infinitas que no permiten conocerlo del todo, el personaje es sólo lo que el film nos muestra de él. Estas operaciones se basan en la selección de momentos claves con el objetivo de otorgarles un alto grado de verosimilitud y coherencia, una identidad estable a los personajes -recurso al que se debe añadir la presencia de la cámara que altera las mismas relaciones que registra-. Uno de los peligros de estas operaciones es la construcción de estereotipos que tienden a tipificar socialmente a los individuos.

Nuestro trabajo se apoya sobre la propuesta de Plantinga, que expone que "los documentales se caracterizan por hablar del mundo real y de personas existentes en él mientras que la ficción, según su propio canon, imagina un mundo e inventa a los personajes irreales que viven en él" $(2007 \text {, p. } 48)^{6}$, resulta ineludible establecer un conjunto de deberes éticos del realizador hacia los sujetos representados. Sin importar que el espectador sea consciente que no se está frente a la persona, sino a una construcción audiovisual -mediada por la cámara-, el documental dice algo sobre un individuo concreto y esto tiene consecuencias. JeanPaul Colleyn (1993) enumera algunas de las defensas comunes ante ciertos comportamientos polémicos: el bien de la causa, las exigencias profesionales, el derecho a la información, el deber de denunciar los abusos, el amor por todo lo que es humano. Pero también propone una serie de preguntas que considera que necesariamente deben hacerse:

$$
\text { ¿Cuánto tiempo podemos "mantener" el plano de }
$$

un hombre llorando? ¿Debemos maquillar como una actriz de televisión a una empleada de oficina, que quiere mostrar la agotadora vida laboral? ¿Podemos mostrar los comentarios que pueden dañar a su autor? ¿Qué significa filmar a alguien en estado de ebriedad? ¿Puedo filmar la muerte bajo una implacabilidad terapéutica? ¿Se debe recurrir a los secretos íntimos de niños con cáncer? ¿A partir de qué grado de dolor o malestar se debe censurar? Todas estas preguntas son una cuestión de moral personal y los cineastas no deben dejar de hacérselas (1993, p. 77).

Muchas veces el cuidado de las personas corre más por cuenta de los realizadores que de los mismos sujetos retratados. Barry Hampe relata, un poco a modo de anécdota, que la pregunta más habitual cuando se pide el permiso de la gente no es "¿para qué va a ser usado?”, sino “¿cuándo saldrá en televisión?” (1997, p. 80). Dejando de lado el tono socarrón adoptado por el autor, la idea propuesta es clara: las posibles consecuencias de una empresa que se caracteriza por tomar la imagen de sujetos para ofrecer una obra de consumo público son en su mayoría desconocidas por los mismos. El reconocido fotógrafo Paul Strand advertía en la década del treinta sobre los riesgos que corre el documentalista al tomar a la persona como un mero material, un objeto. Reflexionando sobre su experiencia en Redes (Fred Zinemann y Emilio Gómez Muriel, 1936), film de ficción que utiliza a actores no profesionales para denunciar la explotación de pescadores mexicanos, el reconocido fotógrafo declaraba: "en un mundo en el que la explotación humana es tan universal, considero otra forma de explotar a la gente -por más pintoresca, diferente o interesante que nos parezca- hacer uso de ellos como un mero material” (en Krippner, 2010, p. 92).

Los realizadores de documentales antropológicos son los que más se han explayado sobre estas cuestiones, debido a que su trabajo con otras culturas demanda una reflexión mayor. En la cinematografía local, una de las figuras principales de este campo fue Jorge Prelorán (1978; 2006), quien en sus escritos dio cuenta de las dificultades con las que lidió en sus películas. El realizador se pregunta cuándo y en qué situaciones es necesario intervenir, recomienda entablar un diálogo con el protagonista sobre las posibles consecuencias de su participación, buscar su colaboración a través de la proyección del film terminado y propone como principio no presentar nada que pudiera causarle daño ni quitarles “el tesoro de la privacidad" (2006, p. 34).

Con este antecedente en mente, recuperamos 
un trabajo reciente de un grupo de investigadores norteamericanos en el que se entrevistaron a 41 realizadores y productores sobre estas cuestiones, se establecieron dos principios generales de conducta: no lastimar a los sujetos y proteger a aquellos vulnerables (Aufderheide et al., 2009, p. 6). La relación entre el sujeto y el (o los) realizadores implica un contrato, un "consentimiento informado", que abarcaría tres etapas: las negociaciones previas al rodaje, la filmación/ entrevista, y el montaje. Las actitudes de los realizadores en cada uno de estos momentos pueden variar, pero el espectador usualmente tiene acceso al registro del encuentro entre las dos partes (más el dispositivo cámara que funciona como catalizador). Si bien en la mayor parte de los casos se cuenta con un contrato físico, existen múltiples vericuetos legales, razón que llevó al documentalista brasileño Eduardo Coutinho a postular que el contrato "(implícito) o es moral o no existe" (2011, p. 102).

En este artículos nos ocuparemos de algunos de los problemas de corte ético que surgen del trabajo con los sujetos y la forma en que son representados. Algunas de las preguntas que ofician de guía son las siguientes: ¿cuáles son las responsabilidades éticas que el realizador de un documental tiene hacia los sujetos que retrata en sus films? ¿Existe alguna forma de representar adecuadamente, una serie de reglas a cumplir, un modelo de contrato (implícito o concreto) entre ambas partes? ¿Cómo debe abordarse la representación de la muerte? Para cumplir con este objetivo focalizaremos nuestra atención sobre tres documentales argentinos recientes que nos permiten trabajar sobre los preguntas formuladas: Yo presidente (Gastón Duprat y Mariano Cohn, 2006), Yo no sé qué me han hecho tus ojos (Sergio Wolf y Lorena Muñoz, 2003) y Bye bye life(Marcelo Piñeyro, 2008).

\section{La interacción con los sujetos}

Yo, presidente de Mariano Cohn y Gastón Duprat se presta a numerosas reflexiones y abordajes sobre la dimensión ética del cine de lo real. El documental consiste en un conjunto de entrevistas a los presidentes argentinos desde el retorno de la democracia hasta el presente de la filmación siguiendo un orden cronológico: desde Raúl Alfonsín a Néstor Kirchner (1983-2006), con las ausencias del último y de Adolfo Rodríguez Saá, quienes se negaron a participar. El primer hecho a resaltar del film es que no intenta ofrecer un retrato positivo de sus personajes, sino justamente lo contrario, algo poco habitual en la filmografía nacional. ${ }^{7}$ Esta decisión no es objetable por sí misma, y podemos preguntarnos si los deberes ante este tipo de personajes son los mismos, pero las estrategias adoptadas por los realizadores son, en más de un caso, como mínimo discutibles, y es en ellas que nos detendremos a continuación.

El segmento inicial, perteneciente al expresidente radical Alfonsín, marca el estilo que se mantendrá en casi todos los casos. Las distintas secuencias abren con la imagen de un perro en alguna situación que cuenta con una carga metafórica, ${ }^{8}$ tras la cual se presenta una secuencia de montaje consistente en los momentos más relevantes de su presidencia -usualmente se componen de la votación, un discurso histórico importante, para pasar rápidamente a una selección de los eventos más discutibles de los distintos mandatos, que dan lugar a entrevistas muy breves. Las entrevistas son presentadas mediante planos detalles del rostro y una utilización peculiar del montaje de sus declaraciones, en el que éstas se superponen unas a otras dificultando su comprensión. Todos estos recursos, pertenecientes a la etapa posterior a la filmación, demuestran que los realizadores no asumen una posición neutra ante los sujetos a la vez que remarcan que son ellos quienes poseen las herramientas de representación.

Sin embargo, el momento más problemático es

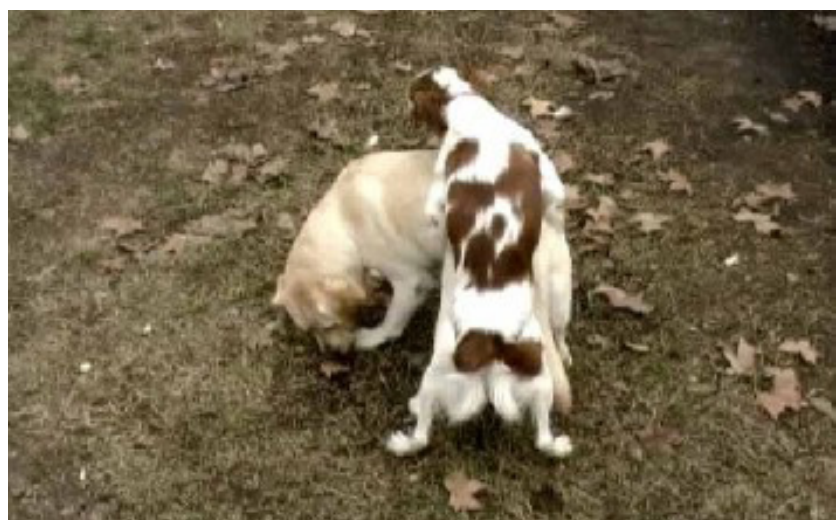

cuando se le pide al entrevistado que haga primero su famoso gesto electoral (la unión de sus dos manos sobre el hombro izquierdo) durante un largo tiempo, pedido que cumple, y luego se lo insta a que lo haga con un movimiento más enérgico, al que también accede, todo mientras se escucha a los realizadores murmurando "Ya está, ya está, basta, basta. Aguantá”. ¿Cuál es el sentido, el propósito, detrás de esta acción? ¿Qué es lo que se está diciendo de esta persona o, formulado distinto, qué faceta 
se agrega a los conocimientos previos del espectador sobre el antiguo mandatario?" La respuesta es ninguna; el diálogo mantenido fuera de cámara revela que el pedido oculta el único objetivo de burlarse. La relación que se establece entre los realizadores y el entrevistado no es sólo asimétrica -en mayor o menor medida, esto siempre es así, debido a que uno tiene mayor acceso a los medios de representación que el otro- sino también deshonesta, practicando una manipulación al no comunicarle al sujeto qué es lo que se pretende hacer con él. En las palabras del teórico Jean-Louis Comolli:

situarse frente al otro, establecer con él una relación particular que pasa por una máquina tiene sentido, compromete una responsabilidad, inclusive si es puramente banal. Dos sujetos se enfrentan -en relación a la máquina- en un duelo, un frente a frente (...) Y si esos dos sujetos no se comprometen uno con otro, la máquina toma nota -cruelmente- de la ausencia de esa relación, de la nulidad del encuentro. No se filma impunemente -y el cuerpo del otro, su palabra, su presencia, menos aún (2007, p. 177).

En última instancia, lo que dicha actitud evidencia es que los realizadores están quebrantando el contrato establecido con el entrevistado, y al violar la confianza de éste consiguen que la empatía del espectador se traslade al sujeto. La inclusión del detrás de escena, con las voces del equipo de filmación, fue articulada por los realizadores como una defensa ante objeciones de falta de objetividad, ${ }^{10}$ pero este recurso por sí mismo no es suficiente para franquear las cuestiones señaladas.

El film avanza presentando las entrevistas a Carlos Saúl Menem y Fernando de la Rúa, las cuales siguen el mismo patrón mencionado, deteniéndose en nimiedades como preguntarle a de la Rúa sobre una foto suya que circuló con una botella de Viagra en el escritorio o pidiéndole que finja que habla por teléfono. Sin embargo, de la misma forma que en este caso la cámara es utilizada como dispositivo para la burla también cumple, por momentos, una función más interesante en la secuencia de Eduardo Duhalde. Si bien toda la primera sección de la entrevista con Duhalde cae en estas mismas trampas, hay un momento en el que éste acerca un álbum de fotos mientras comenta sobre su pasión por la caza de tiburones. En ese momento uno de los entrevistadores le pregunta cómo hacen para subir el pez al barco, a la que responde que antes de hacerlo hay que matarlo pegándole un tiro. Tras un silencio embarazoso el entrevistador, impactado, dice "fuerte", a lo que Duhalde contesta "sí, es lindo". Aquí se lo deja desarrollar al entrevistado, quien expresa sus convicciones, y por ende puede sentirse satisfecho con su retrato sin la necesidad de apelar a los trucos deshonestos de los que hace gala el film en otros de sus pasajes. Si bien ninguna de estas situaciones arroja luz sobre el rol de los entrevistados como mandatarios, es decir en su rol de funcionarios públicos, en este último caso se puede afirmar que la confianza depositada por el sujeto no es violada, y por tanto su representación puede considerarse adecuada.

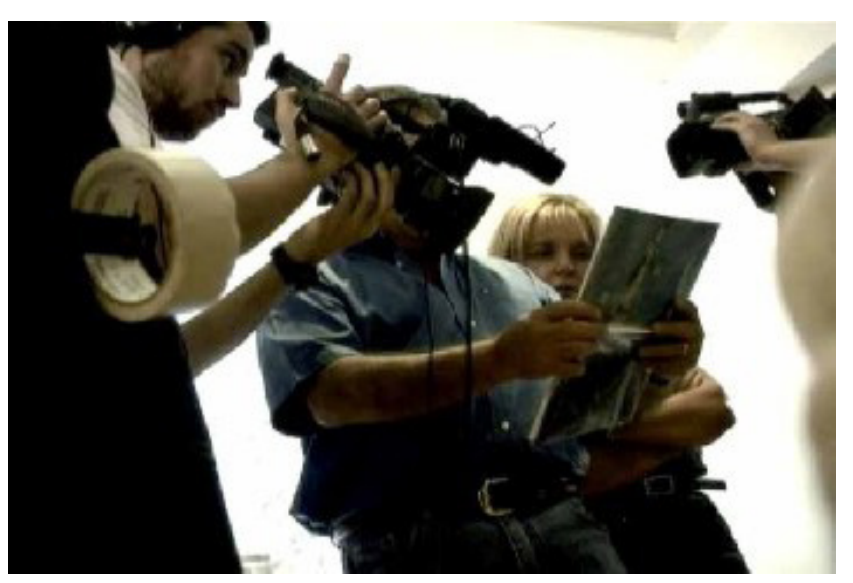

Sobre la competencia del sujeto

El film que analizaremos a continuación establece una relación más compleja con su sujeto que Yo presidente, ya que en aquella no se ocultaba el objetivo de los realizadores de burlarse de sus entrevistados. Yo no sé qué me han becho tus ojos mezcla elementos del documental en primera persona, el documental biográfico y el film noir para narrar la investigación del codirector/protagonista Sergio Wolf, quien a la manera de un investigador privado sacado de las páginas de una novela de Raymond Chandler, se propone rastrear el paradero de la mítica cantante de tango de los años treinta, Ada Falcón.

La primera sección del film concierne a la investigación en la que, mediante entrevistas y material de archivo, se reconstruye la historia de la cantante, sus amoríos, y las supuestas razones que la llevaron a desaparecer de la vida pública por más de seis décadas. En resumen, se reconstruye el mito de la cantante y sus misterios, mientras permanece ausente.

Una vez que los realizadores logran rastrear a Falcón comienza la segunda sección del film que consiste en las entrevistas realizadas a la cantante en el convento del pueblo cordobés de Salsipuedes en donde se recluyó por más de sesenta años. La secuencia dura unos diez 
minutos y comienza con un plano que "espía” desde una puerta a Falcón mientras se maquilla para su entrevista, mientras Wolf dice en off: "sesenta años después vuelve a salir a escena”.

Al comienzo de nuestro trabajo nos referíamos a las principales limitaciones autoimpuestas por los realizadores, principalmente el no lastimar a los sujetos ni dejarlos en una situación peor a la que se encontraban; consideremos entonces con este marco de conducta lo que sucede en esta escena, la situación en la que Wolf y su equipo de filmación irrumpen. Tras un silencio autoimpuesto de seis décadas en los que vivió recluida, la Ada que "sale a escena" difiere mucho de la del retrato que se construyó durante la primer parte de la película. Filmada desde atrás y de perfil, intentando ocultar un parche en su ojo derecho, Wolf le muestra fotos antiguas, una de sus películas y le hace escuchar grabaciones de las que ella no parece tener recuerdos. La voz, la memoria le fallan. "No me oye, no le entiendo", se le escucha decir a Wolf. Como dice Mauricio Alonso, "lo que el mito de Ada Falcón, a lo largo de 60 años, se encargó de poblar de misterio, de zonas turbias y de comentarios equívocos, el film puja por desbrozarlo en sus últimos diez minutos" (2003, p. 179). Los planos intentan presentar la mejor imagen posible de la cantante, pero el espectador siente que Falcón no quiere volver a ver, a rememorar, los objetos (películas, canciones y fotos) que el entrevistador le muestra de forma insistente. Wolf llega a decir en off: "no quiere oírse cantar, me pide que lo saque”, pero las imágenes no lo muestran cumpliendo este pedido, sino que la cámara la toma en unos primeros planos insistentes que reflejan la tristeza y la fragilidad de su cuerpo. Como consecuencia de esta representación, la película claramente deja a la protagonista $-\mathrm{y}$ a su memoria- en una peor situación a la previa del rodaje.

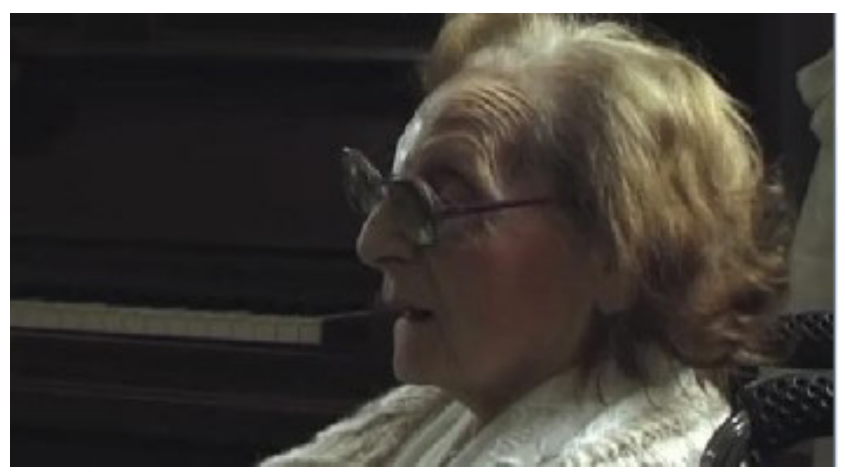

Mientas más débil sea el sujeto representado, más salen a la superficie los problemas de índole ética, por lo que una de las cuestiones centrales a definir es cuáles son las condiciones necesarias que permiten evaluar un consenso previo válido. En la literatura científica se enumeran tres requisitos para que un acuerdo sea considerado como tal: el consentimiento de los sujetos debe haberse conseguido "(1) bajo condiciones libres de coerción y engaño, (2) con conocimiento absoluto del procedimiento y los efectos anticipados, (3) por alguien lo suficientemente competente para dar su consentimiento" (Pryluck, 2005, p. 201). ${ }^{11}$

Si bien el cumplimiento de la primera de estas condiciones está más allá de toda duda -nadie puede alegar que la entrevistada haya sido engañada-, en el caso de las restantes es más discutible. La Ada Falcón que aparece entrevistada se encuentra lejos de encontrarse en control completo de sus facultades, generando la pregunta si es realmente válido filmar a alguien que le huyó a la vida pública durante tantos años durante los últimos días de su vida.

Tras la entrevista hay una pequeña coda en la que se muestra el cementerio donde enterraron a la cantante e imágenes de antiguos teatros y estudios de radios cerrados -o convertidos en estacionamientos-, mientras Wolf declara que "ella ya había muerto muchos años antes". Esta observación parece inscribirse mejor dentro del cine de ficción, lo que demuestra que la adopción de géneros en el documental puede acarrear algunos problemas. ${ }^{12}$ El fallecimiento de Ada Falcón es utilizado por los realizadores como metáfora para la muerte de una época, y es entonces que uno puede preguntarse si es posible utilizar la vida y sobre todo la muerte de un sujeto para ilustrar una tesis, una de las representaciones más complejas del discurso documental como veremos a continuación.

\section{La representación de la muerte}

André Bazin sostuvo que el cine tiene la particularidad de poder capturar el paso del tiempo, de embalsamarlo, produciendo una "momificación del cambio" (2004, p. 29). Siguiendo este razonamiento se puede argumentar que no existe transformación más importante que la que se produce con el paso a la muerte, por lo que es necesario preguntarse cómo encarar el registro de un momento tan trascendental. La teórica estadounidense Vivian Sobchack, en un clásico escrito sobre la representación de la muerte en el documental, propuso una clasificación de miradas sobre la muerte en base a la posición del realizador: la mirada accidental -caracterizada por la 
ausencia de planificación, la sorpresa-, impotente identificada por la lejanía-, en peligro -en una posición próxima-, de intervención -un caso extremo de la anterior-, humana -busca intimidad y simpatía con aquellos que registra- $y$, por último, la profesional que se define por el desapego, se relaciona con el periodismo y es considerada la menos ética (2004, pp. 249-253).

Teniendo en cuenta esta clasificación nos centraremos a continuación en el documentalBye bye life de Marcelo Piñeyro, centrado en los últimos días de vida de la escritora y fotógrafa Gabriela Liffschitz quien falleció de cáncer durante la filmación. El film, según su realizador es sobre "una persona que eligió morirse en un set y otra persona que eligió documentar eso, cuando estas dos personas en verdad tenían otro plan" ${ }^{13}$ La intención original de Piñeyro y Liffschitz consistía en realizar en conjunto un film con representaciones ficcionales de distintas escenas de la vida de la artista, pero al avanzar rápidamente la enfermedad los planes tuvieron que ser alterados ${ }^{14}$. La decisión tomada por Piñeyro fue montar el metraje poniendo el detrás de escena en primer plano, por eso a pesar de que algunas de las escenas actuadas habían sido filmadas no son mostradas al espectador, sino que solo se accede a los preparativos de las mismas; es decir que se privilegia la mostración de la actitud de la artista frente a su enfermedad en sus últimos días.

El comienzo del film presenta la redacción del testamento mientras Liffschitz realiza varias bromas sobre su situación: al ofrecer algo de tomar, pregunta “ ¿jugo, agua, oxígeno?” Momentos después se la muestra subiendo unas escaleras en los brazos del director y otra persona, mientras se la escucha decir que es "otra de las ventajas de tener cáncer".

La siguiente escena, introducida mediante un intertítulo, consiste en el primer día de rodaje en el que la artista se presenta al equipo de producción y los actores para comunicarles la naturaleza del proyecto. En este momento, el espectador puede palpar la tensión y la sorpresa de los presentes cuando son confrontados con Liffschitz, quien mientras les cuenta las historias que deben interpretar bromea constantemente y propone que con las anécdotas de las situaciones que vivió desde que fue diagnosticada debería escribir un libro que sería "para cagarse de risa". Al avanzar la jornada, y ante la sugerencia del realizador, la artista decide abandonar la filmación antes de concluir ya que su enfermedad le dificulta permanecer. En este punto, aproximadamente la mitad del film, Piñeyro introduce una conversación con uno de los técnicos instándolo a que dé su opinión -explicitada previamente en privado al realizador-sobre el proyecto. A pesar de mostrarse un poco reacio al comienzo, finalmente accede y expone que el tratamiento del tema le parece superfluo, que la muerte es un tema sagrado, que no se cree la actitud de "me cago de risa de la muerte", y concluye que el proyecto se resume en filmar a una "mujer que se está muriendo y quiere ser famosa". La inclusión de esta breve escena puede ser leída como una especie de anticipación a las posibles objeciones que se le pueden plantear al film.

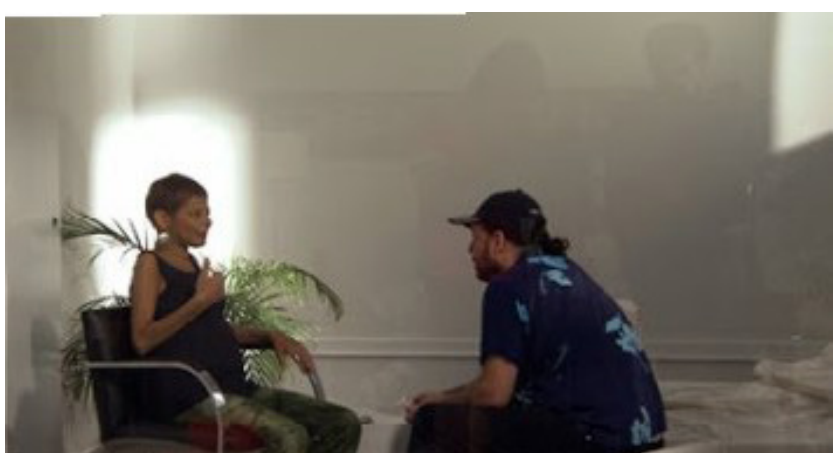

Al siguiente día, Piñeyro decide realizar una entrevista con Liffschitz para comunicarle las críticas expuestas por el técnico, a las que ella responde que si bien le resulta comprensible dicha opinión, "dentro de mis objetivos en los últimos días de mi vida está pasarla bien, divertirme todo lo que pueda... y todo lo que el cuerpo me deje". Esta operación es interesante ya que si bien la temática del documental puede ser discutida, el realizador se asegura de otorgarle la última palabra a Liffschitz a sabiendas de que no podrá exponer sus razones una vez finalizada la película y de que la representación que ofrece se adecua a sus deseos. Un dato a tener en cuenta es que la enfermedad de la artista ya la había obligado a someterse a la ablación de un seno, y tras dicha operación montó un libro con fotografías de su cuerpo buscando convertirse ella misma en una obra de arte. En este sentido, la mirada adoptada por el realizador, recuperando la tipología de Sobchack podría calificarse como humana, ya que busca cumplir con la que sería la última voluntad de la artista. Hay otro momento en el film que sirve para reforzar esta postura, en la que tras sentirse indispuesta termina vomitando. Piñeyro elige mantener únicamente el sonido de la grabación dejando la imagen en negro, pero tras este incidente Liffschitz se retira en un taxi y mientras espera en el asiento trasero hace muecas burlándose de la situación. Si bien uno puede discutir por qué el director decidió dejar (solo el audio de) la escena anterior, es ella quien vuelve sobre la situación, de una forma que intenta ser humorística, para quitarle el pudor a la misma. 


\section{Conclusiones}

La representación de personas en el documental implica responsabilidades éticas que superan las que existen en el cine de ficción. Uno de los testimonios más elocuentes al respecto lo articuló el director polaco Krzysztof Kieslowski, quien reflexionó sobre su paso del documental al terreno de la ficción de la siguiente forma:

Noté mientras realizaba documentales que mientras más intentaba acercarme a un individuo más se cerraban. Probablemente por eso elegí la ficción. Allí no hay problemas. (...) Puedo comprar glicerina, poner gotas en los ojos de una actriz y llorará. He fotografiado lágrimas reales en varias ocasiones. Es algo completamente diferente. Pero ahora tengo glicerina. Tengo miedo a esas lágrimas reales. De hecho, no estoy seguro de tener el derecho de fotografiarlas (1993, pp. 315-316).

Del análisis de los films trabajados se desprenden algunas problemáticas básicas, los personajes retratados no necesariamente deben serlo bajo una luz positiva, pero la pregunta a hacerse es si las consideraciones hacia este tipo de sujetos difieren. ¿Es aceptable utilizar a una persona para demostrar una tesis, servirse de ella como metáfora de una situación que excede la vida del sujeto? ¿Cuáles son los parámetros para delimitar la competencia del sujeto para saber cuáles son las consecuencias que acarrea su participación en un documental? La respuesta a estas preguntas no es fácil ni única, sino que creemos, tal como postula Bill Nichols, que "estas cuestiones se reducen a una cuestión de confianza, una cualidad que no puede legislarse, proponerse o prometerse en lo abstracto tanto como demostrarse, ganarse y concederse en relaciones negociadas, contingentes y concretas en el aquí y ahora" (2007, p. 34). En todo caso, siempre quedan los films como testimonio de la relación establecida entre ambos sujetos y de la ética de sus creadores.

Las obligaciones o códigos de conducta que guían a los realizadores no se encuentran escritas, ni permanecen inalterables, sino que responden a los distintos valores promovidos por las distintas sociedades y van de la mano de las decisiones estéticas adoptadas. Habitualmente la relación que se establece entre el realizador y los sujetos es de franca desigualdad, será la decisión del realizador intentar reducirla o incrementarla. En definitiva, "la película es siempre el reflejo de la relación con los personajes, y esa relación siempre está primero que la película en sí” (Prelorán, 2006, p. 36).

\section{Referencias}

Alonso, M. (2003). “Distancias”, en Kilómetro 111, n5. Buenos Aires: Santiago Arcos Editor, pp. 176-181.

Aufederheird, P., Jaszi, P., y Chandra, M. (2009). Honest Truths: Documentary Filmmakers on Ethical Challenges in Their Work. Washington: Center for Social Media. Disponible en: http://centerforsocialmedia.org/making-your-media-matter/documents/bestpractices/honest-truths-documentary-filmmakers-ethical-chall

Barnouw, E. (1996). El documental. Historia y estilo. Barcelona: Gedisa editorial.

Bazin, A. (2004). “Ontología de la imagen fotográfica”, en ¿Qué es el cine? Madrid: Ediciones RIALP, pp. 23-32.

Colleyn, J. (1993). Le regard documentaire. Paris: Editions du centre Pompidou.

Comolli, J.L. (1997). “¿Cómo filmar al enemigo?”, en Ver y poder. Buenos Aires: Nueva Librería, pp. 371-383.

Comolli, J.L. (1994). “La otra escucha... Práctica y teoría de la entrevista”, en Ver y poder. Buenos Aires: Nueva Librería, pp. 177180.

Coutinho, E., Xavier, I., y Furtado, J. (2011). “El sujeto (extra)ordinario”, en El cine de lo real. Buenos Aires: Colihue, pp. 77-115.

Crowder-Taraborrelli, T. (2012). "Verdades honestas: la ética en el cine documental”, enRevista Cine Documental n 5 . Buenos Aires. Disponible en: http://revista.cinedocumental.com.ar/5/teoria_02.html

Kieslowski, K. (1993). “The Unique Role of Documentaries”, en Cousins, M. y McDonald, K. (eds.): 2006. Imagining Reality. The Faber Book of Documentary. Londres: Faber \& Faber, pp. 312-316

Krippner, J. (2010). Paul Strand in Mexico. New York: Aperture Fundation.

Hampe, B. (1997). Making documentary films and reality videos. A Practical Guide to Planning, Filming, and Editing Documentaries of Real Events. New York: Henry Holt and Company, Inc.

Kalow, N. (2011). Visual Storytelling. The Digital Video Documentary. North Carolina: CDS Publication. Disponible en http:// documentarystudies.duke.edu/uploads/media_items/visual-storytelling-the-digital-video-documentary.original.pdf

Mendoza, C. (2008). La invención de la verdad: nueve ensayos sobre cine documental. México: Universidad Nacional Autónoma de 
México.

Nichols, B. (2007). “Cuestiones de ética y cine documental”, en Archivos de la Filmotecan57, Valencia: Ediciones de la Filmoteca, pp.27-45.

Nichols, B. (1997). La representación de la realidad. Cuestiones y conceptos sobre el documental. Barcelona: Paidós.

Niney, F. (2009). La prueba de lo real en la pantalla. Ensayo sobre el principio de realidad documental. México: Universidad Nacional Autónoma de México, Centro Universitario de Estudios Cinematográficos.

Noriega, G. y Panozzo, M. (2006). “Traicionamos el género documental”. Revista El Amante. Octubre, N 173.

Pena de Oliveira, F. (2009). Teoría del periodismo. México: Alfaomega.

Pessoa Ramos, F. (2008). Mas afinal... O que é mesmo documentário? São Paulo: Editora Senac.

Plantinga, C. (2007). “Caracterización y ética en el género documental”, en Archivos de la Filmoteca no 57, Valencia: Ediciones de la Filmoteca, pp. 46-67.

Plantinga, C. (1997). Rhetoric and Representation in Nonfiction Film. New York: Cambridge University Press.

Pryluck, C. (2005). "Ultimately We Are All Outsiders: The Ethics of Documentary Filming” en Rosenthal, A., y Corner, J. (eds.) New Challenges for Documentary. Manchester: Manchester University Press, pp. 194-208.

Prelorán, J. (2006). El cine etnobiográfico. Buenos Aires: Catálogos.

Prelorán, J. (1978). El cine documental etnobiográfico de Jorge Prelorán. Buenos Aires: Ediciones Búsqueda.

Rothman, W. (1998). “The filmmaker as hunter”, en Grant, B. K. y Sloniowski, J. (eds.):Documenting the documentary. Close readings of Documentary Film and Video. Detroit: Wayne State University Press, pp. 23-39.

Ruby, J. (2005). “The Ethics of Image Making; or, 'They're Going to Put Me in the Movies. They're Going to Make a Big Star Out of Me...”, en Rosenthal, A., y Corner, J. (eds.) New Challenges for Documentary. Manchester: Manchester University Press, pp. 209-219.

Sobchack, V. (2004) “Inscribing Ethical Space. Ten Propositions on Death, Representation and Documentary”, en Carnal Thoughts. Embodiment and Moving Image Culture. California: University of California Press, pp. 226-257.

Winston, B. (2005) “Ethics”, en Rosenthal, A., y Corner, J. (eds.) New Challenges for Documentary. Manchester: Manchester University Press, pp. 181-193.

Filmografía mencionada

Bye bye life (2008), de Enrique Piñeyro

Man of Aran (1934), de John Grierson

Nanook of the North (1922), de Robert Flaherty

Redes (1936), de Fred Zinnemann y Emilio Gómez Muriel

Roger y yo (Roger and Me, 1989), de Michael Moore

Yo no sé qué me han hecho tus ojos (2003), de Sergio Wolf y Lorena Muñoz

Yo presidente (2006), de Gastón Duprat y Mariano Cohn

1 En el caso del periodismo podemos citar a modo de ejemplo el Código de ética del periodista brasileño reproducido en Pena de Oliveira, el cual "fija las normas a las que deberá subordinarse la actuación del profesional en sus relaciones con la comunidad, las fuentes de información y entre los propios periodistas” (2009, p. 132). En la Argentina, el Foro de Periodismo Argentina (FOPEA) ha redactado un Código de Ética para la práctica periodística en el año 2006, el cual se encuentra disponible en su página web: http:// www.fopea.org/etica-y-calidad/codigo-de-etica-de-fopea/

2 Ver entrevista de Harlan Jacobson al cineasta reproducida en Ortega y García (2008).

3 Sobre este punto ver principalmente Bruzzi (2000), quien remarca el criterio evolutivo, en un sentido positivista, que se puede inferir de los planteos de Nichols.

$4 \quad$ Las controversias alrededor de las películas de Flaherty están detalladas en múltiples investigaciones, entre ellas Barnouw (1996) y Rothman (1998). El mismo Flaherty declaró tiempo después sobre Mano of Aran: “debí haber sido fusilado por lo que le pedí hacer para la película a esa gente tan noble, por los riesgos a los que los expuse” (en Niney, 2009, p. 94).

5 Un repaso sobre esta polémica se puede encontrar en el libro de Mark Harris Five Came Back: A Story of Hollywood and The Second World War (2014). 
6 El famoso legal disclaimer (aviso legal) de las películas de ficción en el que se declara que "los hechos y/o personajes que aparecen en esta obra son ficcionales. Cualquier semejanza con personas reales, vivas o muertas, es pura coincidencia” constituye una elocuente muestra de esta diferencia.

7 El ya mencionado Prelorán recomendaba retratar a un ser "positivo": “encontrar un ser con una imagen positiva es importante -viéndolo en la pantalla-, es alguien con el cual la audiencia puede establecer empatía, alguien a quien es fácil llegar a respetar; un ser que nos lleve a querer escucharlo, a querer entender -nosotros los de afuera-, los secretos de su cultura” (2006, p. 36).

8 Ante la secuencia de Alfonsín un perro defecando, para Menem dos perros manteniendo sexo, con De la Rúa durmiendo la siesta, etc.

$9 \quad$ En este sentido es necesario remarcar que las personas que aparecen tanto en este documental como en los que nos ocuparemos a continuación son personalidades famosas, pertenecientes en mayor o menor medida a la esfera pública.

10 En una entrevista a los directores, Mariano Cohn reflexionaba: "En algún momento nos preguntaron si no traicionamos a los tipos con esto, y yo siento que traicionamos un poco al género documental. Uno no está acostumbrado a que salgan los cuchicheos de detrás de cámara. Ni tampoco a que alguien manipule de manera tan violenta o con tanta intervención al discurso de alguien. Pero lo nuestro está blanqueado" (Noriega y Panozzo, 2006, p. 14-15).

11 En Kalow (2011) se puede encontrar un modelo de contrato, en el cual se puede comprobar el carácter vago que poseen.

12 Una última cuestión a señalar con respecto a este film no concierne a la representación del sujeto, sino al espectador y tiene que ver con la cronología de los acontecimientos. La entrevista realizada a Falcón fue el primer material filmado para la película, y con la obtención del mismo se construyó la estructura narrativa. En este caso, el film adopta una modalidad performativa y la alteración del orden de los hechos no concierne a la realidad afílmica, por lo que esto no representa un problema.

13 Entrevista en video disponible en: http://weblogs.clarin.com/camara-libre/2008/04/14/bye_bye_life_para_el_que_se_anime/

14 Liffschitz cayó en coma el día siguiente de finalizado el rodaje, falleciendo dos días más tarde. 